\title{
Augmented Vector Right
}

National Cancer Institute

\section{Source}

National Cancer Institute. Augmented Vector Right. NCI Thesaurus. Code C90362.

An aug mented unipolar electrocardiog ram limb lead in which the positive (white)

electrode is situated on the right thoracic limb and the negative electrode is a

combination of the left thoracic limb (black) electrode and the left pelvic limb (red)

electrode. Measures the electrical activity of the electrode on the right thoracic limb. 